\title{
Aqua-planet simulations of the formation of the South Atlantic convergence zone
}

\author{
Rosana Nieto Ferreira ${ }^{\mathrm{a} *}$ and Winston C. Chao ${ }^{\mathrm{b}}$ \\ a Department of Geography, East Carolina University, Greenville, NC, USA \\ ${ }^{\mathrm{b}}$ Global Modeling and Assimilation Office, NASA/Goddard Space Flight Center, Greenbelt, MD, USA
}

\begin{abstract}
The impact of Amazon Basin convection and cold fronts on the formation and maintenance of the South Atlantic convergence zone (SACZ) is studied using aqua-planet simulations with a general circulation model. In the model, a circular patch of warm sea-surface temperature (SST) is used to mimic the effect of the Amazon Basin on South American monsoon convection. The aqua-planet simulations were designed to study the effect of the strength and latitude of Amazon Basin convection on the formation of the SACZ. The simulations indicate that the strength of the SACZ increases as the Amazon convection intensifies and is moved away from the equator. Of the two controls studied here, the latitude of the Amazon convection exerts the strongest effect on the strength of the SACZ. An analysis of the synoptic-scale variability in the simulations shows the importance of frontal systems in the formation of the aqua-planet SACZ. Composite time series of frontal systems that occurred in the simulations show that a robust SACZ occurs when fronts penetrate into the subtropics and become stationary there as they cross eastward of the longitude of the Amazon Basin. Moisture convergence associated with these frontal systems produces rainfall not along the model SACZ region and along a large portion of the northern model Amazon Basin. Simulations in which the warm SST patch was too weak or too close to the equator did not produce frontal systems that extended into the tropics and became stationary, and did not form a SACZ. In the model, the SACZ forms as Amazon Basin convection strengthens and migrates far enough southward to allow frontal systems to penetrate into the tropics and stall over South America. This result is in agreement with observations that the SACZ tends to form after the onset of the monsoon season in the Amazon Basin. Copyright (C) 2012 Royal Meteorological Society
\end{abstract}

KEY WORDS South American monsoon; cold fronts; SACZ

Received 25 September 2011; Revised 5 February 2012; Accepted 5 February 2012

\section{Introduction}

A hallmark feature of the mature South American monsoon system (SAMS), the South Atlantic convergence zone (SACZ), is easily identified in time-averaged maps of austral summer rainfall as a distinctive northwest-southeast oriented band of rainfall that connects the western Amazon Basin and the South Atlantic Ocean (Figure 1). This climatological SACZ can be thought of as a time-averaged manifestation of stationary frontal zones. On sub-monthly timescales each SACZ episode is composed of one or more cold fronts that intrude into the tropics and subtropics and become stationary for several days over southeastern Brazil. Once established, the SACZ has strong variability on intraseasonal timescales (e.g. Mathews et al., 1996; Liebmann et al., 1999; Nieto-Ferreira et al., 2003; Carvalho et al., 2004) and modulates winds and the amount and organization of rainfall well into the Western Amazon Basin (Rickenbach et al., 2002).

\footnotetext{
* Correspondence to: R. Nieto Ferreira, Department of Geography, East Carolina University, Greenville, NC 28590, USA.

E-mail: ferreirar@ecu.edu
}

It has been suggested that the formation of the SACZ is closely connected to the onset of the SAMS (NietoFerreira and Rickenbach, 2010, hereafter NR10). The term SAMS encompasses the rainfall over the Amazon Basin and the SACZ. The former is often referred to as a tropical monsoon (like the South Asian monsoon) and the latter a subtropical monsoon (like the East Asian monsoon). It is noted that the two components have different characteristics and different mechanisms of formation. This study addresses, among other things, the role of the tropical monsoon in the formation of the subtropical monsoon. The onset of the SAMS has complex temporal and regional variability (Kousky, 1988; Liebmann and Marengo, 2001; Marengo et al., 2001; $\mathrm{Li}$ and $\mathrm{Fu}$, 2004; Horel et al., 1989; NR10) that is controlled by local and remote land-ocean-atmosphere processes. NR10 proposed a three-stage conceptual model for SAMS onset. According to this model, stage 1 of monsoon onset begins around pentad 58 (13-17 October) when precipitation starts in northwestern South America and then gradually progresses south and southeastward. Stage 2 of monsoon onset is marked by the abrupt onset of rainfall in the SACZ around pentad 61 (28 October to 1 November). Stage 3 involves the late arrival of the monsoon to the mouth of the Amazon River, associated with the slow 


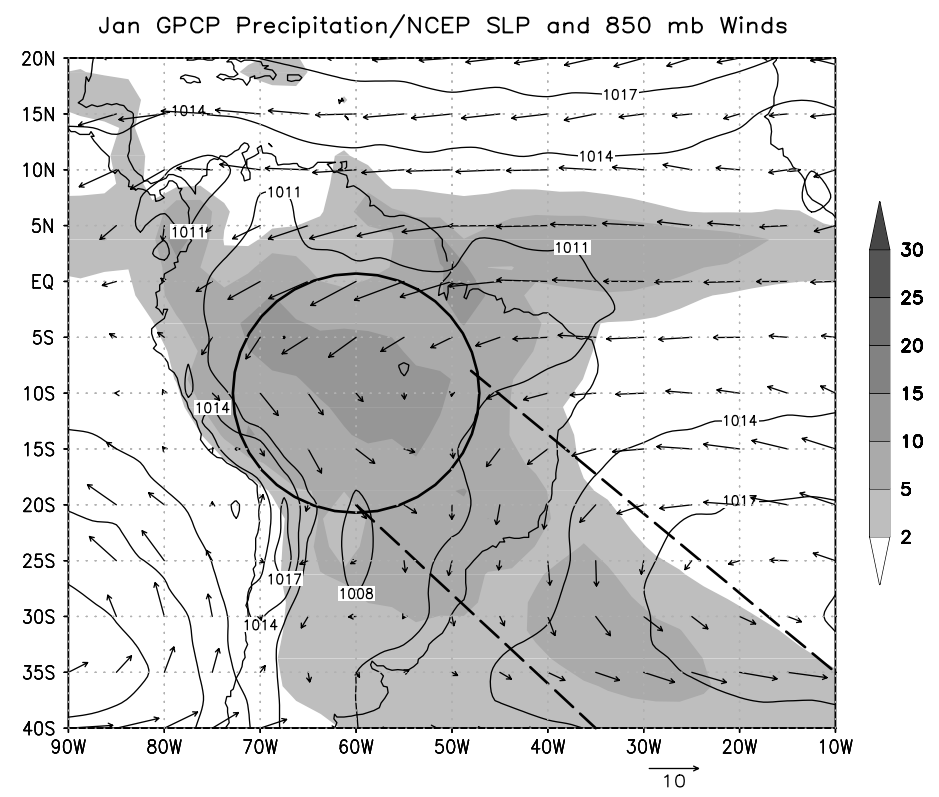

Figure 1. Rainfall climatology (shaded, $\mathrm{mm} \mathrm{d}^{-1}$ ) from the Global Precipitation Climatology Product and sea-level pressure (contours, hPa) $850 \mathrm{hPa}$ winds (arrows, $\mathrm{m} \mathrm{s}^{-1}$ ) climatology from the National Center for Environmental Prediction Reanalysis dataset. The solid circle indicates the location of the strongest Amazon Basin Rainfall, and the dashed lines indicate the location of the SACZ.

southward migration of the Atlantic intertropical convergence zone (ITCZ, Biasutti et al., 2004). This three-stage model of SAMS onset highlights regional differences in monsoon onset mechanisms. While the gradual onset of the monsoon season in the Amazon Basin is likely driven by the gradual buildup of convective available potential energy in the atmosphere associated with the southward migration of the sun $(\mathrm{Li}$ and $\mathrm{Fu}, 2004 ; \mathrm{Fu}$ and $\mathrm{Li}, 2004)$, the abrupt onset of the monsoon season in the SACZ region is very likely dynamically driven (e.g. Nieto-Ferreira et al., 2011, hereafter NRW11, Li and Fu, 2006; Raia and Cavalcanti, 2008).

The mechanisms for the formation of the SACZ have been addressed in previous observation and modelling studies. For instance, Kodama $(1992,1993)$ suggests that subtropical convergence zones such as the SACZ occur in regions where: (1) an upper-level subtropical jet is present and (2) low-level poleward flow is present along the western side of the subtropical high. An observational study by NRW11 used composites of the observed structure and propagation of cold fronts that occur prior to, during, and after the onset of the rainy season in the SACZ region to show the importance of cold fronts on the abrupt establishment of the SACZ. They found that at the time of monsoon onset in the SACZ cold fronts suddenly stall over South America and become organized into a northwest-southeast-oriented band of rainfall that stretches from northwestern Amazonia to the Atlantic Ocean, persisting for several days. Their results therefore suggest that a sudden change in the structure and propagation of cold fronts causes the abrupt onset of rainfall in the SACZ. Their results moreover suggested that this change in the behaviour of frontal systems at the time of the onset of rainfall in the SACZ is associated with a change in the upper-level evolution of the mid-latitude cyclones from a broadening to a thinning trough behaviour (e.g. Thorncroft et al., 1993).

Previous modelling studies have demonstrated that the presence of Amazon convection is essential for the formation of the SACZ. In these studies whether the Amazon convection was produced by fluxes from an underlying forest in more realistic general circulation model (GCM) simulations or by fluxes from a near-equatorial region of warm sea-surface temperatures (SSTs) in an aqua-planet GCM, it was clear that the SACZ can only occur in the presence of a continental-scale region of tropical convection such as the one present in the Amazon Basin during the SAMS (e.g. Lenters and Cook, 1995). Most modelling studies also agree that the presence of the Andes Mountains is not essential for the formation of the SACZ (e.g. Kodama, 1999; Chao and Chen, 2001). One exception is the regional modelling study of Figueroa et al. (1995), which suggested that both the Amazon convection and the Andes Mountains are essential for the formation of the SACZ.

The effect of the strength of the mid-latitude upperlevel jet on the formation of subtropical convergence zones was studied by Yoshikane and Kimura (2003). Using a regional climate model they showed that in the presence of the Australian continent and observed austral summer SSTs the intensity of the South Pacific convergence zone (SPCZ) depends on the intensity of the upperlevel zonal wind speed and baroclinicity of the midlatitude flow. In their model weaker mid-latitude baroclinicity leads to a weaker or entirely suppressed SPCZ.

Aqua-planet simulations by Kodama (1999) showed that a strong localized off-equatorial warm SST anomaly in the tropics can form a very realistic subtropical convergence zone without any influence of topography or land-sea distribution. The intraseasonal variability of the 
aqua-planet subtropical convergence zones is characterized by active and break periods. During active periods the aqua-planet subtropical convergence zones share many of the characteristics of observed subtropical convergence zones such as strong rainfall, moisture flux convergence, and strong poleward moisture flow from the tropics (Kodama, 1999). This study also suggests that the presence of an elongated trough that extends through the entire troposphere on the western poleward side of the subtropical convergence zone is forced by latent heat release in the subtropical convergence zone. The role of mid-latitude cyclones and fronts was not discussed. The low-level poleward flow of moist air along the subtropical convergence zone was attributed to latent heat release in the subtropical convergence zone.

This study uses aqua-planet simulations with a general circulation model of the atmosphere (AGCM) to study the formation of the SACZ region. More specifically, it addresses the effect of the latitude and strength of a synoptic-scale region of convection in the tropics (such as the Amazon Basin convection) on the structure and the propagation of mid-latitude frontal systems and on the formation of a subtropical convergence zone (such as the SACZ). The paper is organized as follows. Section 2 outlines the set-up of the aqua-planet GCM simulations. Section 3 shows results of the aquaplanet GCM simulations. Conclusions are summarized in Section 4.

\section{Aqua-planet model and experiment design}

The model used in this study is the NASA/Goddard's Earth Observing System atmospheric general circulation model version 5 (GEOS-5 GCM) simplified to an aquaplanet setting in which all land is replaced by ocean with an idealized SST distribution that is fixed in time and space. The space vacated by the landmass is filled with air so that the globally averaged sea-level pressure (SLP) is not changed. The GEOS-5 GCM uses the finite-volume dynamical core of Lin (2004). For the planetary boundary layer (PBL) the GEOS-GCM uses a combined PBL and turbulence package developed by Louis (1979) for the stable PBL and Lock et al. (2000) for the unstable and cloud-capped PBL. Radiation is treated using the shortwave radiation scheme of Chou and Suarez (1999) and the long-wave radiation scheme of Chou et al. (2001). Clouds are parameterized using the relaxed ArakawaSchubert (RAS) scheme for moist convection (Moorthi and Suarez, 1992) and a prognostic cloud scheme that includes a rain re-evaporation scheme (Bacmeister et al., 2006). Rainfall is partitioned into convective, large-scale, and anvil components. The convective rain comes from the cumulus parameterizaton scheme (RAS scheme by Moorthi and Suarez, 1992), large-scale rain comes from the saturation of a grid box and the subsequent falling raindrops or snow reaching the surface, and anvil rain comes from the detrained water substance at the top of cumulus clouds. The re-evaporation of precipitation substance is taken into account separately with a different rate for each convective component. The model also includes gravity wave and land surface parameterizations, but they are not relevant to this study. An aqua-planet model based on an earlier version of this model was used by Chao and Chen (2004). A brief description of the aqua-planet set-up used in this study is presented below.

The model resolution is $2^{\circ}$ in latitude and $2.5^{\circ}$ in longitude with 72 vertical levels. The simulations are run in perpetual January mode for 144 days, including a 30 days spin-up period that was excluded from the analysis below. All simulations use a zonally symmetric background north-south SST distribution that has maximum SST at the equator. The initial conditions are from the end of a long run with this background SST. In addition to the background zonally symmetric SST, each simulation has a $10^{\circ}$ radius warm SST patch centred in the Southern Hemisphere near the equator (the SST distribution for the experiment CONTROL is shown in Figure 2). In the model, the warm SST patch simulates the presence of the Amazon Basin and therefore the convection that occurs over the warm SST patch is meant to represent convection that occurs in the real-world Amazon Basin.

\section{Aqua-planet simulations}

As the SAMS progresses into its mature stage, convection in the Amazon Basin strengthens and migrates southward (e.g. NR10). Observations presented in NR10 suggest that the onset of the monsoon season in the Amazon Basin precedes the formation of the SACZ. NR10 also shows that while over the Amazon Basin the onset of the monsoon season progresses slowly southward during the austral Spring, the onset of the rainy season in the SACZ occurs abruptly when a frontal system becomes stationary over southeast Brazil sometime in the late austral Spring. The effects of the latitude and strength of the Amazon Basin convection on the formation of the SACZ are studied here. In the aqua-planet model the Amazon Basin is simulated by a $10^{\circ}$ radius patch of warm SST placed near the equator in the Southern Hemisphere. In the model, the latitude and strength of the Amazon convection are controlled by the central latitude and strength of the warm anomaly in the SST patch, respectively. The warmer the SST patch, the stronger the convection it will produce. The parameters used in each model simulation are listed in Table I. Figure 2 shows the SST distribution for the CONTROL simulation.

\subsection{Time-averaged model SACZ}

Figure 3 shows the 114 day mean rainfall, SLP and $850 \mathrm{hPa}$ winds for each aqua-planet simulation. The solid circle indicates the size and location of the idealized patch of warm SST (or model Amazon) and the dashed lines delimit the location of the model SACZ in experiment CONTROL.

The first three experiments, CONTROL (Figure 3(a)), WEAK (Figure 3(b)), and STRONG (Figure 3(c)), were 


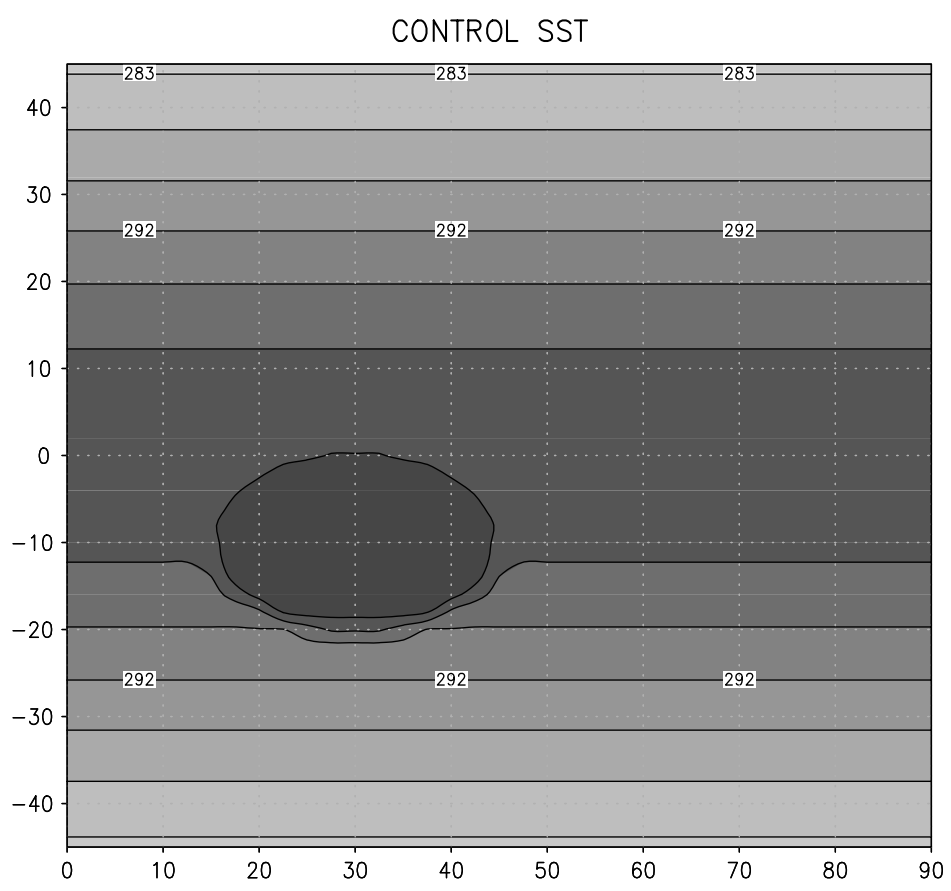

Figure 2. Sea-surface temperature $\left({ }^{\circ} \mathrm{K}\right)$ used in experiment CONTROL.

Table I. Parameters used to specify the location and intensity of the SST patch in each model simulation.

\begin{tabular}{lcc}
\hline Simulation & LAT0 & SST_ANOM \\
\hline CONTROL & $10^{\circ} \mathrm{S}$ & 4 \\
WEAK & $10^{\circ} \mathrm{S}$ & 2 \\
STRONG & $10^{\circ} \mathrm{S}$ & 6 \\
EQUATOR & 0 & 4 \\
5_SOUTH & $5^{\circ} \mathrm{S}$ & 4 \\
15_SOUTH & $15^{\circ} \mathrm{S}$ & 4 \\
\hline
\end{tabular}

LAT0 refers to the latitude where the warm SST patch is centred and SST_ANOM refers to the strength of the SST anomaly (in degrees Celsius) in the warm SST patch.

designed to analyse the effect of the strength of Amazon convection upon the characteristics of the SACZ. This was done by changing the strength of the SST anomaly in the circular patch of warm water added to each experiment (Table I) while keeping their latitude the same (Table I). Although the warm SST patch is nearly circular, all three experiments produce a northwest-southeastoriented region of rainfall that extends southeastward from the model Amazon convection (Figure 3(a)-(c)) in a way that resembles the real-world SACZ. Here this feature is referred to as the model SACZ. The northwest-southeast-orientation and southeastward extent of the model SACZ in these three experiments are very similar. All three experiments have model SACZs that extend near or into the subtropics. Another common feature of all experiments is that the model SACZ rainfall is strongest in the tropics just to the southeast of the model Amazon convection. In the discussion below the intensity and southeastward extent of the rainfall in the SACZ region (delimited by the dashed lines in Figure 3) are used as an indicator of the strength of the SACZ features in the model simulations. In that sense, the SST anomaly in experiment WEAK (Figure 3(b)) produces a weaker model SACZ feature than does the stronger SST anomaly in experiment STRONG (Figure 3(c)). This set of experiments indicates that for a fixed latitude, the stronger the Amazon rainfall, the stronger the SACZ the model produces.

Other than in the model SACZ, no significant rainfall occurs in the subtropics in any of the aqua-planet experiments indicating that the presence of a synoptic-scale region of convection in the tropics (such as the Amazon Basin convection) is essential for the formation of a subtropical convergence zone such as the SACZ.

Three additional experiments (5_SOUTH, 15_SOUTH, and EQUATOR) were designed to investigate the effect of the north-south migration of convection over South America upon the formation of the SACZ. In this set of experiments the central latitude of the SST patch changes but the strength of the imposed SST patch anomaly is kept the same (Table I). However, given the fact that these experiments are run using a background zonally symmetric SST distribution with warmer SSTs in the tropics than in the extratropics, the closer the SST patch is to the equator, the stronger the total SST anomaly in the region of the SST patch. This is evidenced for example by the presence of larger amounts of rainfall within the model Amazon in experiments EQUATOR (Figure 3(d)) and 5_SOUTH (Figure 3(e)) than in experiment 15_SOUTH (Figure 3(f)). In spite of the presence of stronger rainfall in the SST patch region in experiments EQUATOR and 5_SOUTH, these experiments produce only an incipient model SACZ feature that does not extend very far southeastward. On the other hand, despite the presence of weaker rainfall in the SST 


\section{Mean Precipitation, SLP, and $850 \mathrm{mb}$ Winds}

(a) CONTROL

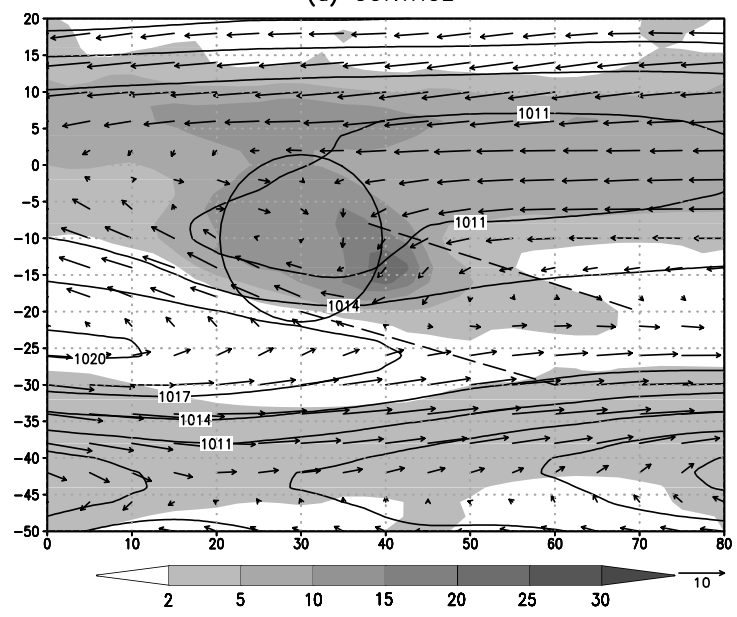

(b) WEAK

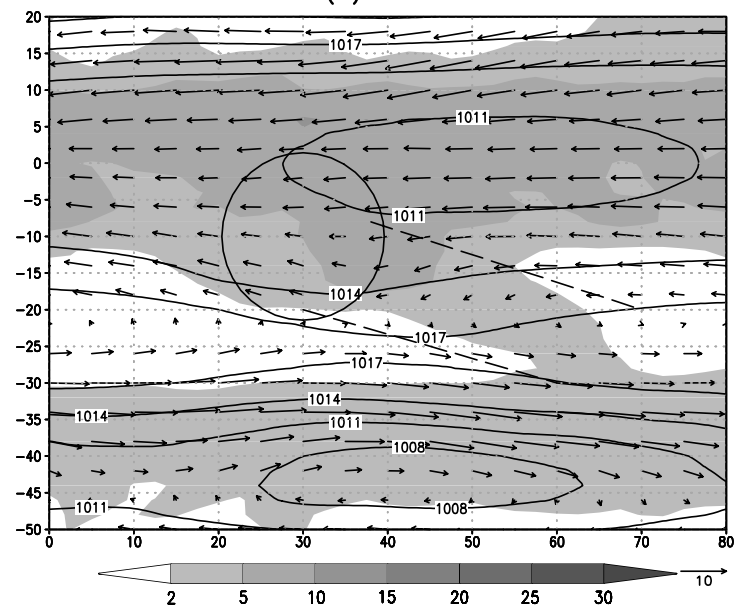

(c) STRONG

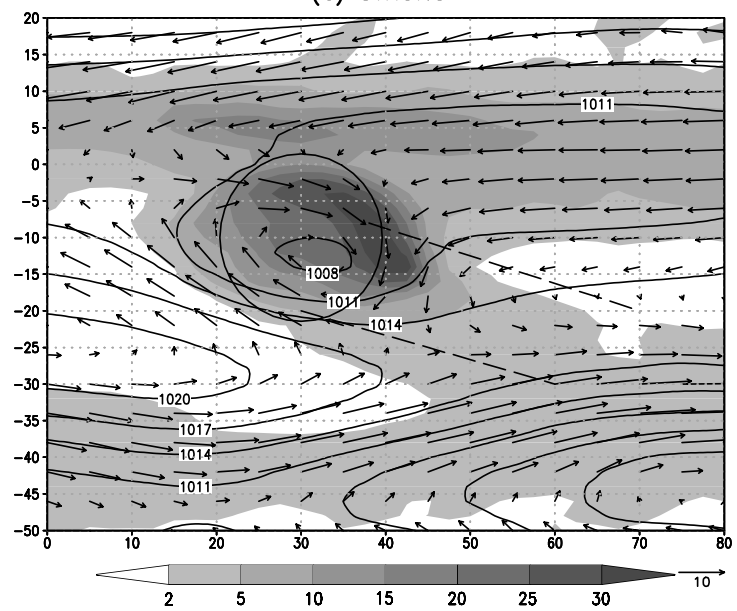

(d) EQUATOR

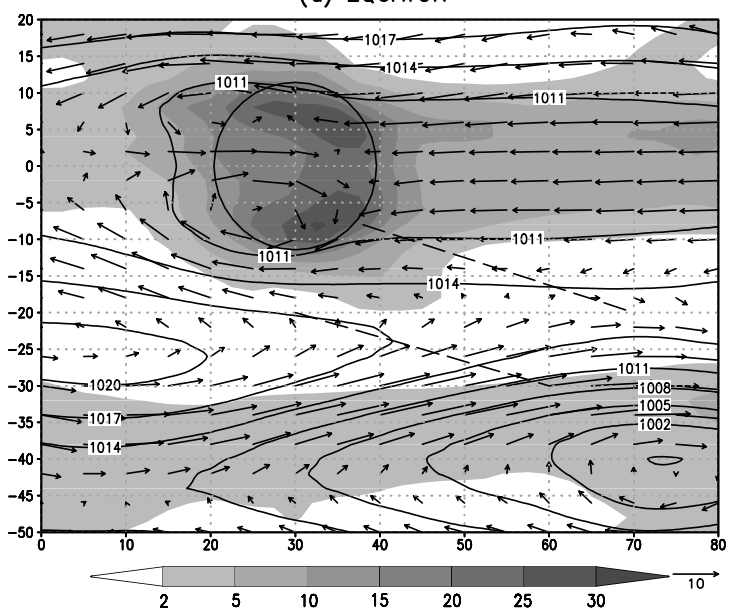

(e) 5_SOUTH

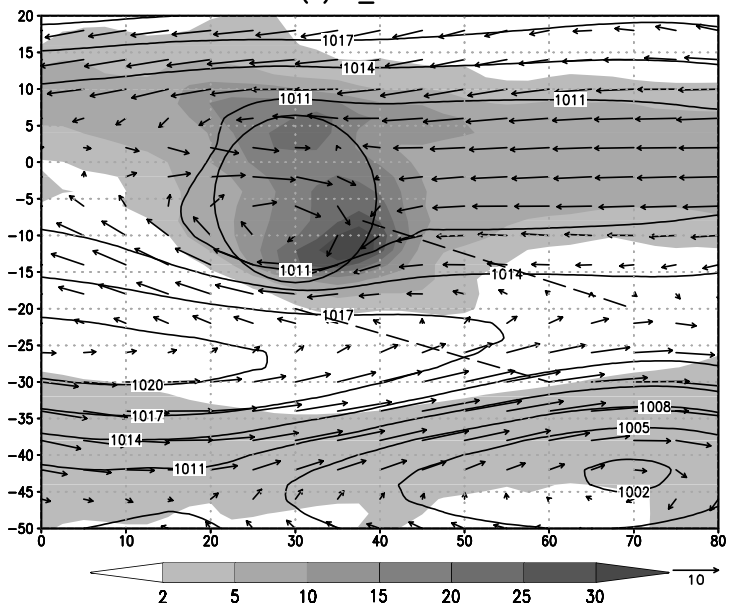

(f) 15_SOUTH

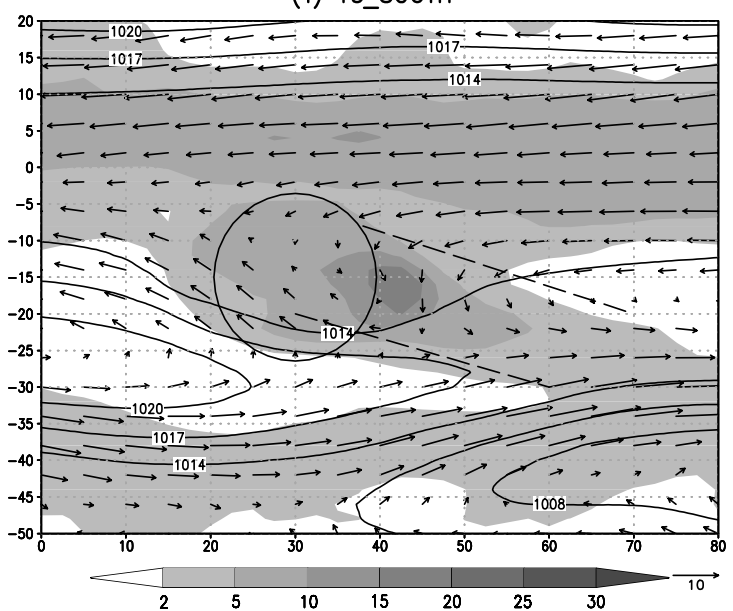

Figure 3. Mean rainfall (shaded, $\mathrm{mm} \mathrm{day}^{-1}$ ), sea-level pressure (contours, hPa), and $850 \mathrm{hPa}$ winds (arrows, $\mathrm{m} \mathrm{s}^{-1}$ ) for each aqua-planet model experiment. The solid circle indicates the size and location of the imposed warm patch of SST, and the dashed lines indicate the location of the model SACZ in experiment CONTROL.

patch region, experiment 15_SOUTH (Figure 3(f)) produces a strong, well-defined SACZ feature that extends into the extratropics and connects with the rainfall in the mid-latitudes. This second set of experiments suggests that (1) the central latitude of the SST patch is more important than its intensity for the formation of a strong, well-defined model SACZ that extends into the extratropics and (2) the model SACZ tends to strengthen and extend further into the extratropics as the SST patch is moved away from the equator (in agreement with results from aqua-planet simulations shown by Kodama, 1999). 
Although the SST patch in experiment EQUATOR (Figure 3(d)) is centred at the equator, there is an asymmetry in the precipitation and wind fields with respect to the equator that is a result of the fact that the simulation is run in a perpetual January mode. In experiment EQUATOR (Figure 3(d)) two strong rainy centres straddle the equator just outside the northeastern and southeastern quadrants of the warm SST patch. Similar to experiment 5_SOUTH (Figure 3(e)) an incipient model SACZ that does not extend very far southeastward forms in experiment EQUATOR (Figure 3(d)).

Together, the aqua-planet simulations described above indicate that the establishment of the SACZ is favoured most importantly not only by the southward migration of the SST patch, but also by the strength of the SST patch anomaly. This result is in agreement with the NR10 observation that the real-world SACZ tends to form after the monsoon becomes established in the Amazon Basin.

Although in the absence of the Andes Mountains it is not possible to reproduce details of the circulation over the South American continent (Gandu and Geisler, 1991), the low-level winds associated with experiments CONTROL (Figure 3(a)), STRONG (Figure 3(c)), and 15_SOUTH (Figure 3(f)) show the presence of a lowlevel poleward jet between about 10 and $20^{\circ} \mathrm{S}$ along the southeastern side of the warm SST patch region. This feature resembles the poleward jet present along the observed SACZ (Figure 1). The presence of this lowlevel poleward jet is required for the formation of an SACZ (e.g. Kodama, 1993). In the aqua-planet model simulations the poleward low-level jet can be thought of as part of the Rossby-wave induced cyclonic circulation produced by the convection over the warm SST patch (e.g. Silva Dias et al., 1983).

The role of synoptic-scale moisture convergence in maintaining SACZ rainfall is explored in the water budget for the CONTROL experiment shown in Figure 4. Precipitation is equal to the sum of evaporation and vertically integrated moisture flux convergence. Evaporation (Figure 4(b)) dominates as the source of moisture to feed rainfall in the southern portion of the model Amazon convection. On the other hand, vertically integrated moisture flux convergence (Figure 4(c)) is the dominant source of moisture to maintain rainfall over most of the model Amazon and over the model SACZ. This is in good agreement with Kodama's (1992) observation that moisture flux convergence maintains the high rainfall rates observed in all subtropical convergence zones, including the SACZ. The region of strong moisture flux convergence extends southeastward from the northwestern portion of the model Amazon Basin into the Atlantic Ocean, a pattern that is consistent with the idea that frontal systems play an important role in producing the model SACZ. Further support for this idea is given below.

\subsection{Frontal systems and SACZ formation}

To gain further insight into the mechanisms for formation and maintenance of the SACZ, composite timeseries of cold fronts crossing the model Amazon Basin longitude band are analysed in this section.

Similar to NRW11, the passage of frontal systems to the south of the model Amazon Basin was detected using the timeseries of daily SLP at $20^{\circ} \mathrm{S}, 50^{\circ} \mathrm{E}$. A frontal system passage was defined as the time when a minimum occurred in the SLP timeseries that was preceded by at least a $3 \mathrm{hPa}$ drop over a 2 day period. On the basis of this definition, at least eight frontal system events occurred at $20^{\circ} \mathrm{S}, 50^{\circ} \mathrm{E}$ in each simulation. For each simulation the eight strongest frontal systems were used to build a 6 day-long composite timeseries of rainfall, SLP, and winds associated with frontal systems that passed through the longitude band of the model Amazon.

The composite timeseries of SLP, rainfall, and $850 \mathrm{hPa}$ winds for experiment CONTROL (Figure 5) shows an eastward propagating mid-latitude cyclone that is characterized by the presence of a low pressure centre (located at $40^{\circ} \mathrm{S}, 40^{\circ} \mathrm{E}$ on day 0 , Figure 5(c)), cyclonic winds, and the telltale northwest-southeast-elongated rainfall signature of a cold front. The concomitant $200 \mathrm{hPa}$ geopotential anomalies (Figure 6) indicate the presence of an upper-level eastward propagating mid-latitude trough that remains about a quarter of a wavelength westward of the surface low pressure centre as is characteristic of an eastward propagating mid-latitude cyclone. As the midlatitude cyclone approaches the model Amazon longitude band on day -1 (Figure 5(b)) and day 0 (Figure 5(c)), rainfall increases in the tropics over the northwestern portion of the model Amazon region (solid circles in Figure 5) likely helping deepen the stationary heat low over the model Amazon. This deepening of the heat low is accompanied by enhanced low-level cyclonic winds and enhanced northwesterly winds across the eastern side of the model Amazon. Note the strong pressure gradient between the heat low in the model Amazon and the subtropical high. As the mid-latitude cyclone propagates eastward it displaces the subtropical high eastward creating a strong east-west pressure gradient between the heat low and the subtropical high and producing strong lowlevel northwesterly winds across the model Amazon on day -1 (Figure 5(b)). Meanwhile winds with an easterly component still prevail in the subtropics. As the midlatitude cyclone passes to the south of the model Amazon between day -1 (Figure 5(b)) and day +1 (Figure 5(d)) and the subtropical high continues to be displaced eastward by the mid-latitude cyclone, the subtropical winds rotate to produce a well-developed northwesterly jet that acts as a conduit to carry moisture from the tropics to the extratropics and enhance rainfall in the model SACZ region. The presence of a northwesterly jet that persists for several days in these composites is consistent with the observations of a northwesterly jet across the Amazon Basin during active periods of the SACZ (e.g. Rickenbach et al., 2002). The enhanced frontal rainfall associated with the mid-latitude cyclone remains in the SACZ region during all 6 days of the composite timeseries even as the mid-latitude low pressure centre continues to propagate eastward. The passage of the 


\section{CONTROL Water Budget}

(a) Precipitation ( $\mathrm{mm} /$ day)

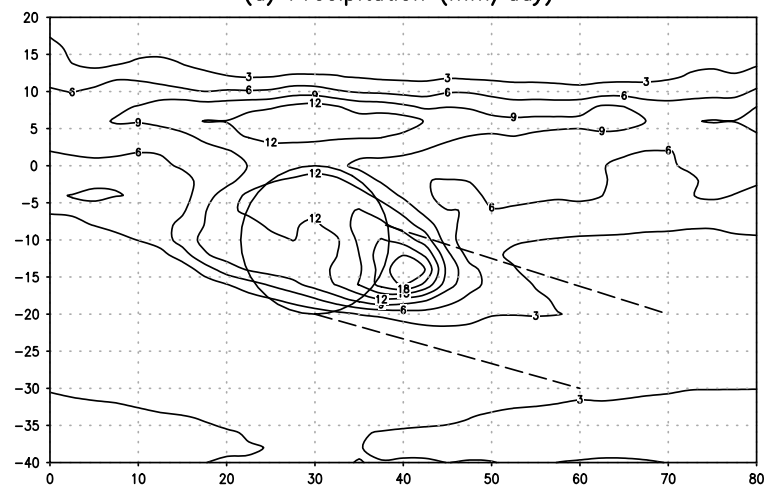

(b) Evaporation ( $\mathrm{mm} /$ day)

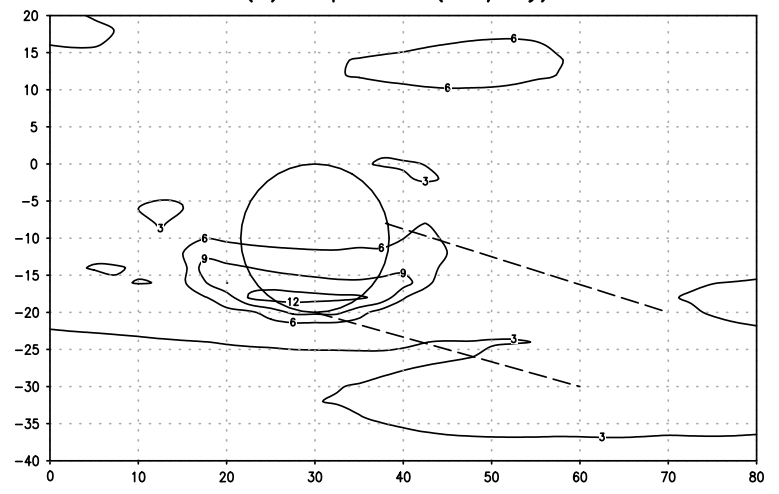

(c) Vertically Integrated Moisture Flux Convergence ( $\mathrm{mm} /$ day)

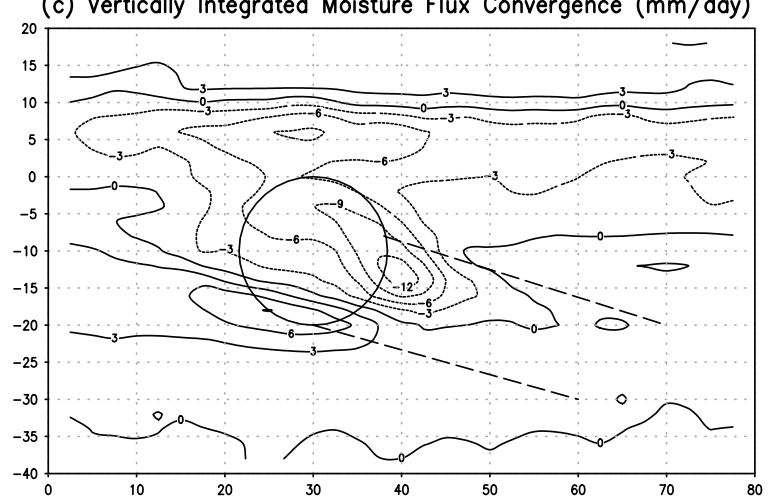

(d) $P-E+$ VIMFC

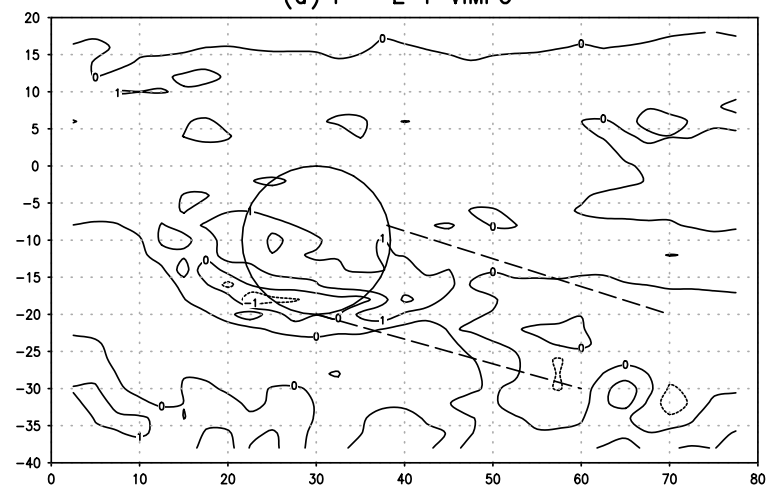

Figure 4. (a) Rainfall, (b) evaporation, (c) vertically integrated moisture flux convergence, and (d) residual for experiment CONTROL. Units are $\mathrm{mm} \mathrm{day}^{-1}$.

mid-latitude cyclone organizes a northwest-southeastoriented band of enhanced rainfall that stretches from the northwesternmost reaches of the model Amazon into the mid-latitudes between days 0 and 3 (Figure 5(c)-(f)) in a way that is very similar to the effect of observed summertime frontal passages shown by Garreaud (2000) and NRW11. In the meantime, the mid-latitude rainfall associated with the mid-latitude cyclone continues to propagate eastward with the cyclone. Note also how the isobars show that the low-level trough adopts an increasingly pronounced NW-SE tilt as it propagates past the longitude of the model Amazon. Figure 7 shows the composite timeseries of the vertically integrated moisture flux for the CONTROL experiment. After the tropical and midlatitude rainfall become connected forming one NW-SEoriented band of convection on day 0 (Figure 7(c)), a dramatic increase in vertically integrated moisture flux occurs in the subtropics contributing to the formation of the model SACZ (Figure 7(c)-(f)) and leading also to the deepening of the mid-latitude cyclone as it continues to propagate eastward (Figure 5(d) and (f)). Lastly, the frontal system evolution in the aqua-planet composite timeseries shown in Figure 5 bears remarkable similarity to the composites of observed frontal systems passing through South America during the spring and summertime after the onset of the rainy season in the SACZ (NRW11). The frontal system evolution in the aqua-planet simulations shown here is also similar to the observed temporal evolution of the SACZ shown in previous studies (e.g. Liebmann et al., 1999; Carvalho et al., 2002, 2004).

As mentioned earlier, the only subtropical region of rainfall (or model SACZ) in the CONTROL experiment occurs to the southeast of the tropical region of convection (or model Amazon Basin) and is produced by the presence of the imposed warm SST patch. The question of why the model SACZ only occurs in the presence of the model Amazon Basin can be addressed in part by repeating the composite analysis for a longitude further east in the CONTROL simulation $\left(120^{\circ} \mathrm{E}\right)$. Although an eastward propagating mid-latitude cyclone is also present in this composite (Figure 8), it is clear that in the absence of the model Amazon's rainfall, no tropical heat low and therefore no tropical or subtropical low-level northwesterly winds are present. The vertically integrated moisture flux convergence along the frontal systems in this composite (Figure 9(a)) is much weaker than that associated with the frontal systems that propagate past the model Amazon region (Figure 7(c)). Hence at this longitude the rainfall associated with the mid-latitude cyclone does not stretch into the subtropics and tropics and no model SACZ can form.

The picture that emerges from the composite timeseries in Figures 5 and 7 is that in the presence of a tropical region of convection that is centred to the south of the equator (such as the model Amazon Basin) fronts are 
CONTROL Front Composites

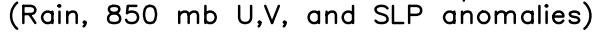

(a) Day -2

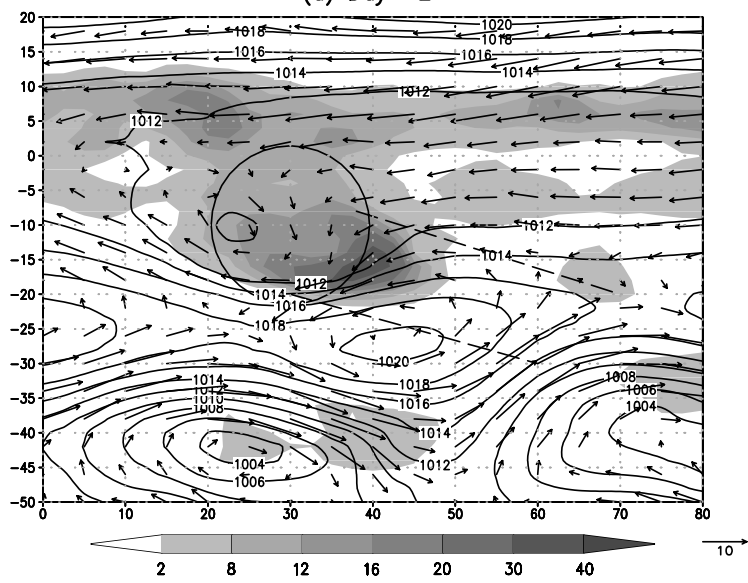

(b) Day -1

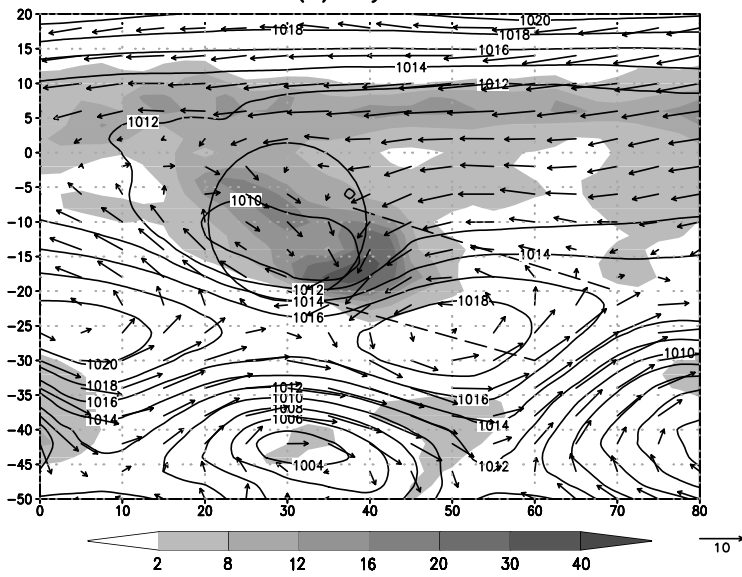

(c) Day 0

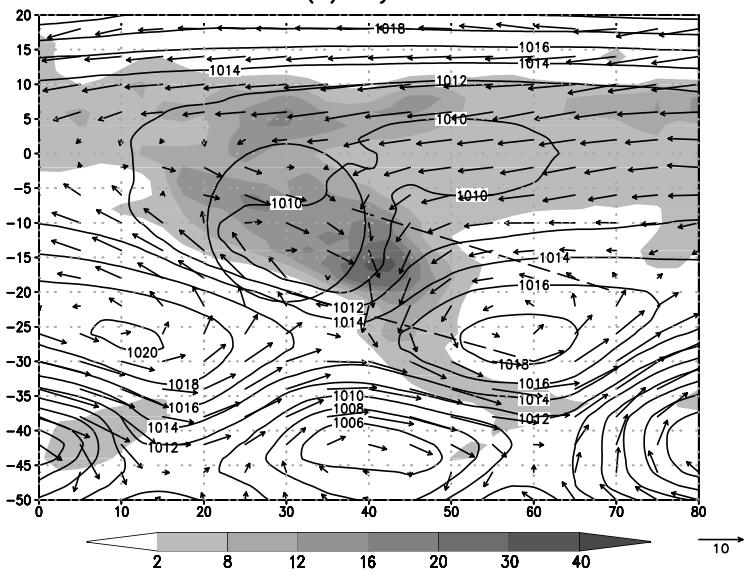

(d) Day +1

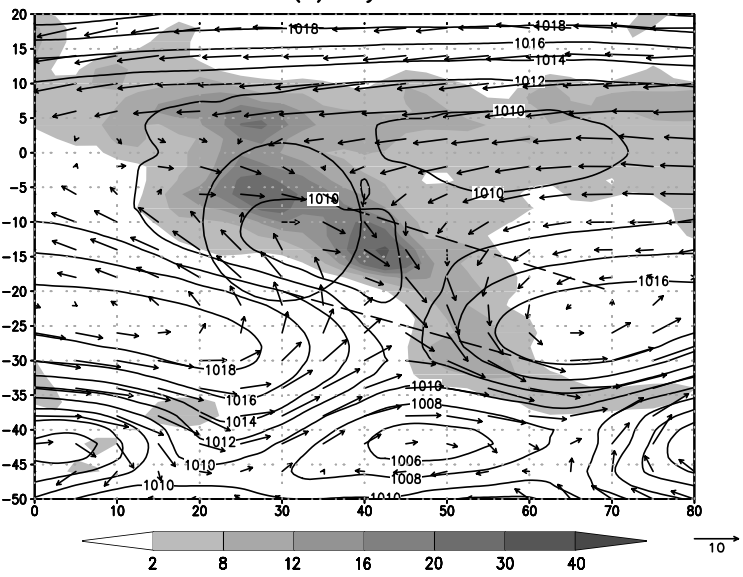

(e) Day +2

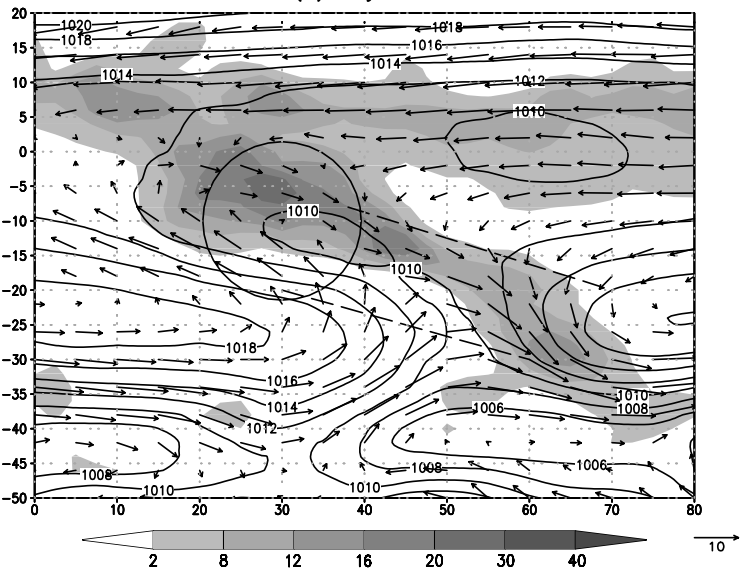

(f) Day +3

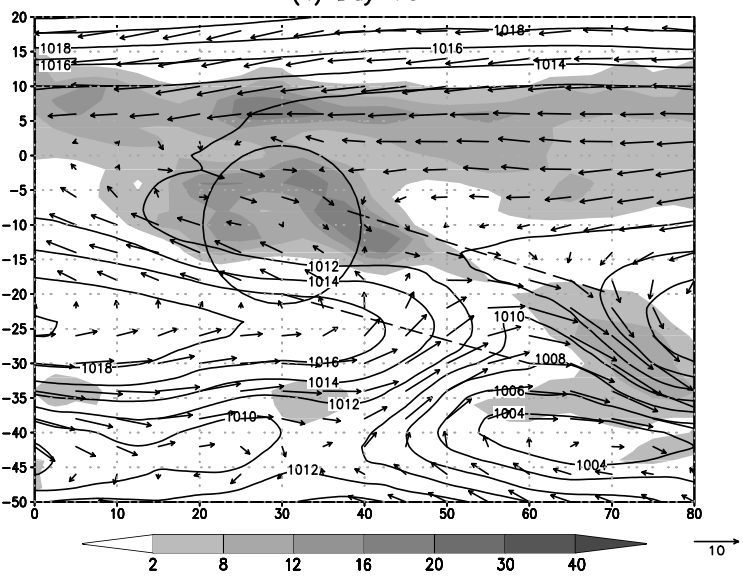

Figure 5. Composite timeseries of rainfall (shaded, $\mathrm{mm} \mathrm{d}^{-1}$ ), SLP (contours, hPa), and low-level winds (arrows, $\mathrm{m} \mathrm{s}^{-1}$ ) for frontal systems that passed through the model Amazon longitude in experiment CONTROL. The solid circle indicates the size and location of the imposed warm patch of SST and the dashed parallel lines in the subtropics delimit the location of the model SACZ in experiment CONTROL.

able to extend into the subtropics and tropics and become stationary allowing a model SACZ to form. Under those circumstances moisture convergence associated with frontal systems (Figure 7) enhances rainfall in the subtropics along the model SACZ region and also along a large portion of the northern model Amazon Basin.
As shown in Figure 3(b) the cooler SST patch imposed in experiment WEAK not only produces weaker rainfall in the Amazon Basin but also a weaker model SACZ feature. To understand how these differences relate to frontal system passage through the region, Figure 10 shows the composite timeseries for frontal passages in 
CONTROL Front Composites

(Rain, $200 \mathrm{mb}$ Phi Anomaly)

(a) Day -2

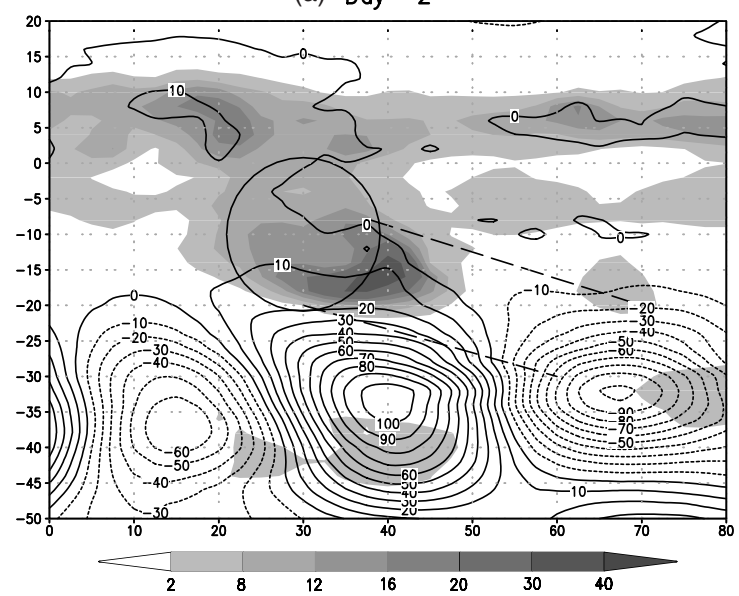

(c) Day -1

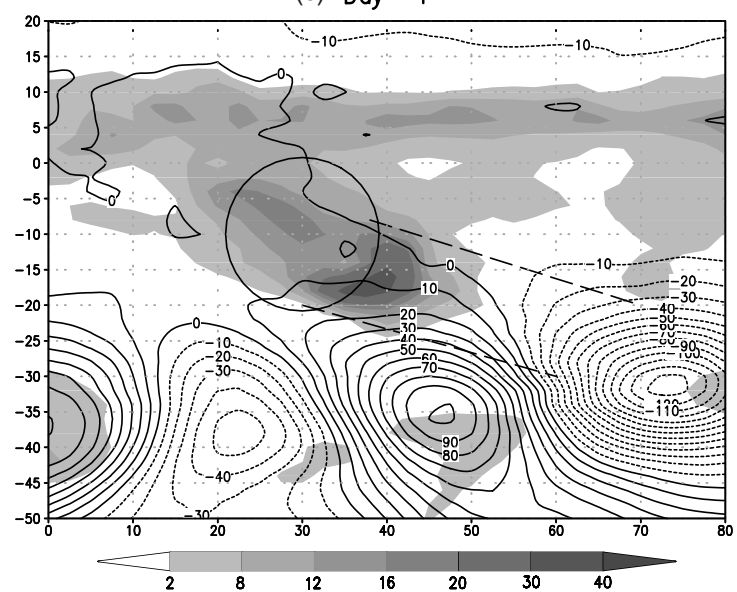

(e) Day 0

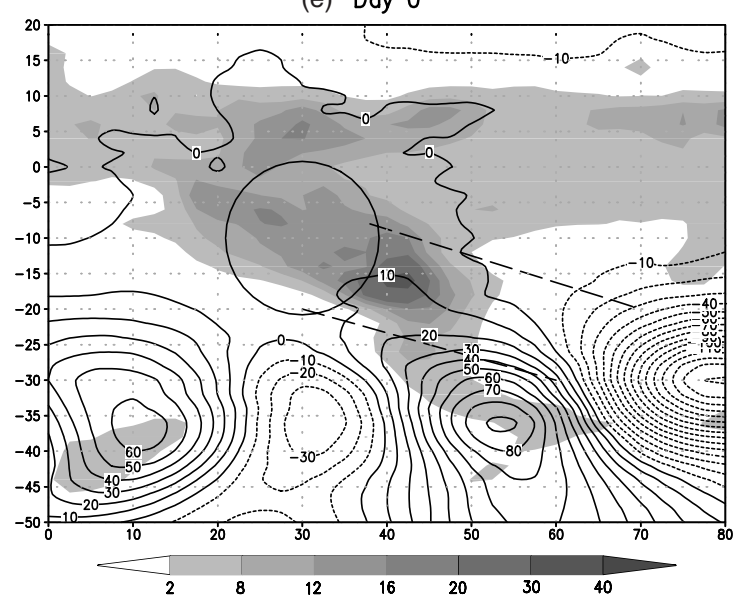

(b) Day +1

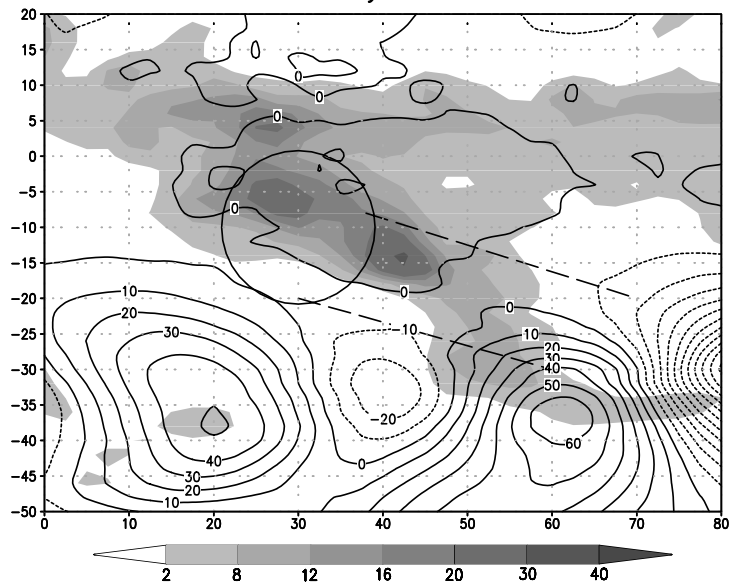

(d) Day +2

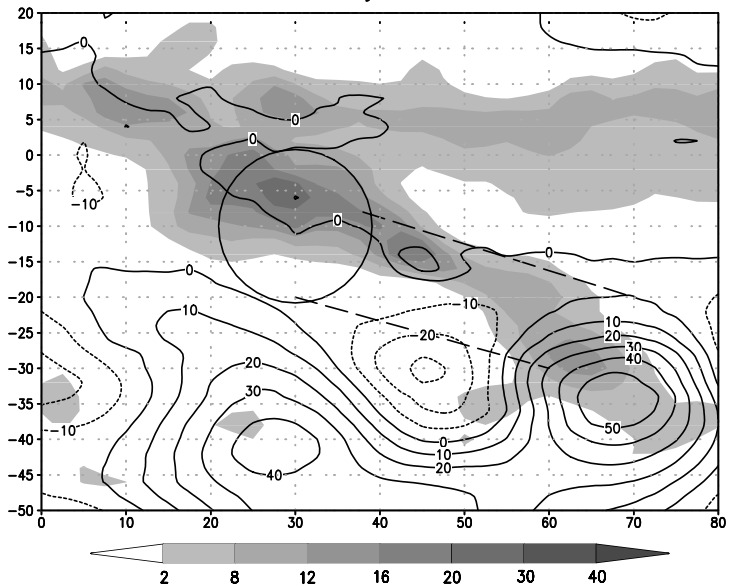

(f) Day +3

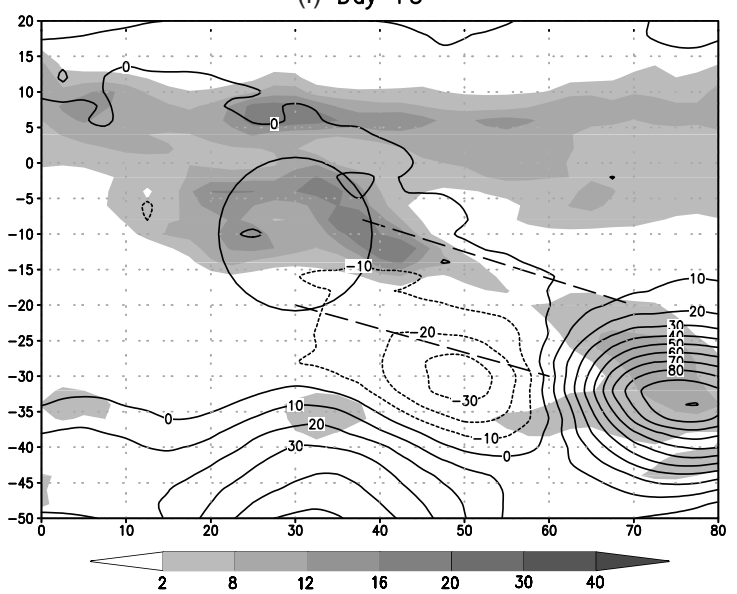

Figure 6. Same as Figure 5 but for rainfall (shaded, $\mathrm{mm} \mathrm{d}^{-1}$ ), and 200-mb geopotential anomalies (contours, $\mathrm{m}$ ).

experiment WEAK. While an eastward propagating midlatitude cyclone is clearly present during the composite frontal passage in experiment WEAK (Figure 10), rainfall in the model SACZ region is weaker and does not last as long as that in experiment CONTROL (Figure 5). Unlike the CONTROL experiment, the very weak northwesterly low-level jet in WEAK does not extend into the Amazon region and carries little moisture from the tropics to higher latitudes. The vertically integrated moisture convergence in the WEAK (Figure 9(b)) front composites is therefore much weaker when compared with that in the CONTROL experiment near the model Amazon (Figure 7(c)). Front composites for the 5_SOUTH simulation (not shown) show mid-latitude cyclones that produce no rainfall in the model SACZ region as they propagate past the longitude of the model Amazon. 
CONTROL Front Composites

(Vertically Integrated moisture flux)

(a) Day -2

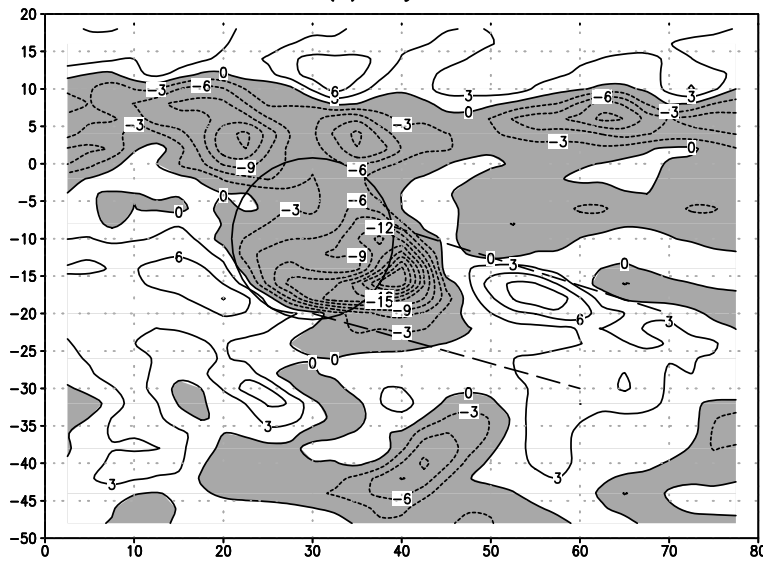

(b) Day -1

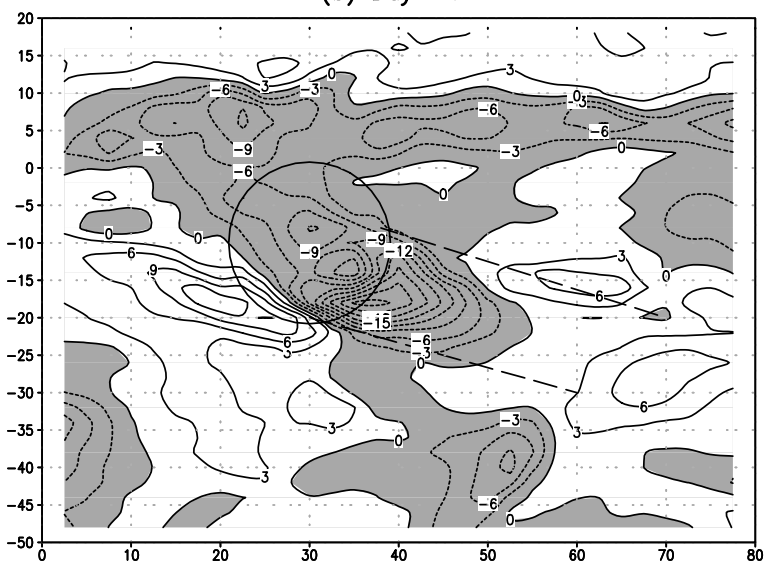

(c) Day 0

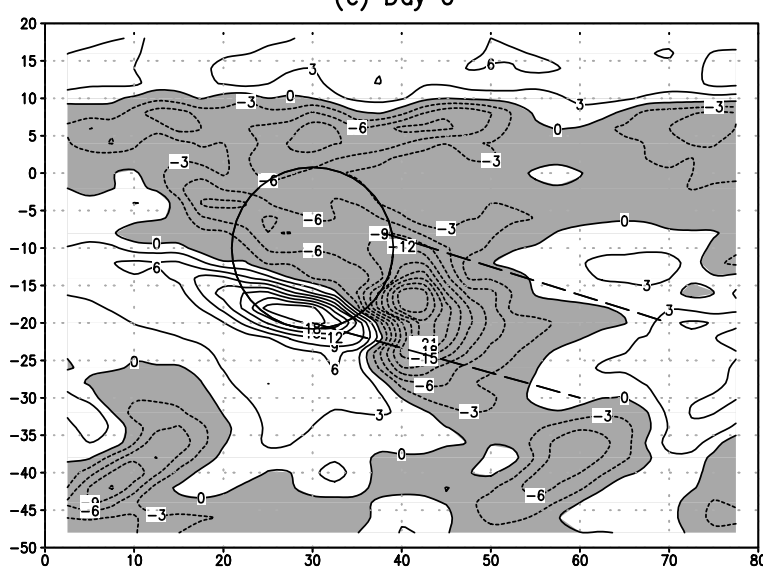

(d) Day +2

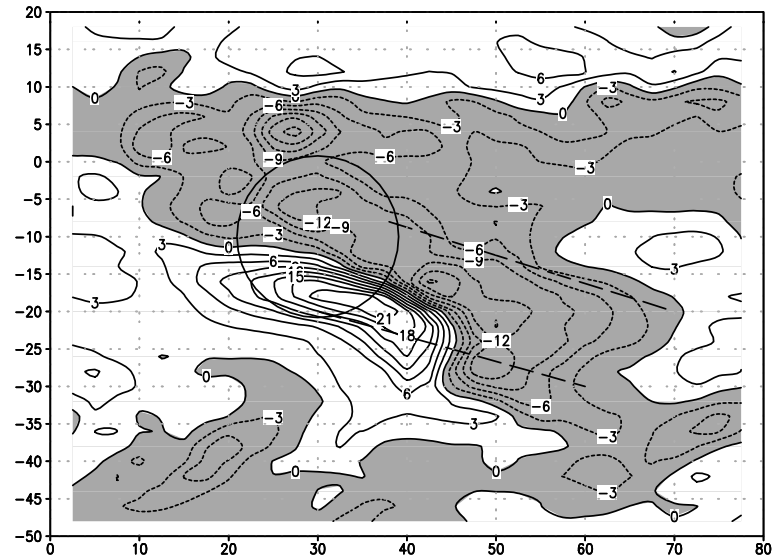

(e) Day +2

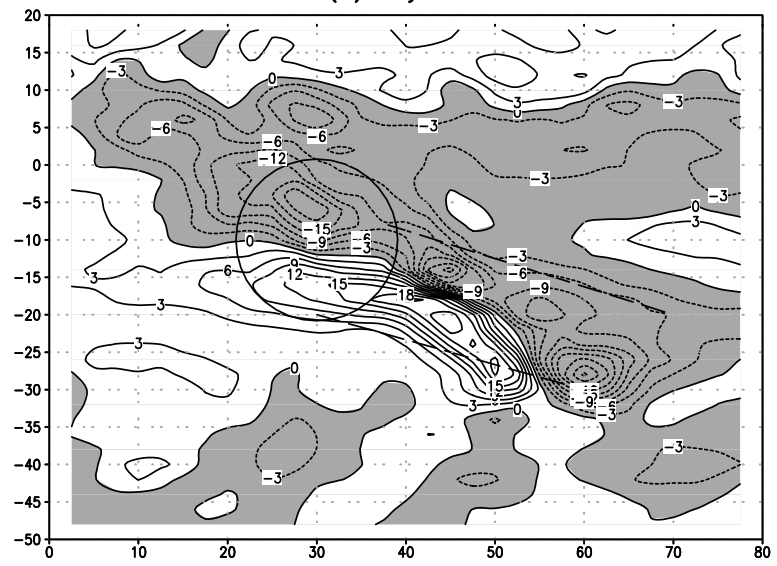

(f) Day +3

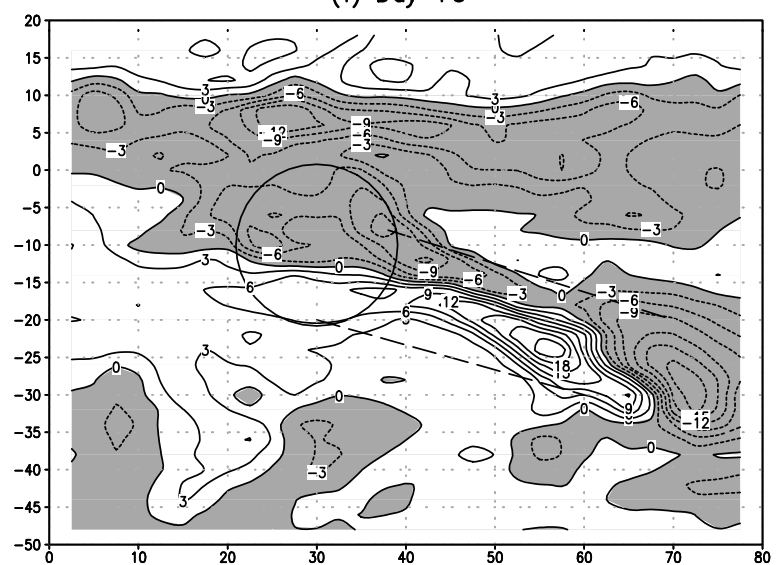

Figure 7. Same as Figure 5 but for vertically integrated moisture flux (contours, $\mathrm{mm} \mathrm{d}^{-1}$ ).

The above composite analysis of aqua-model experiments shows that the presence of a region of enhanced convection centred away from the equator is needed to allow frontal rain to extend into the subtropics and remain stationary there for a few days producing a subtropical convergence zone. The front composites also suggest that if the region of enhanced convection is too weak or too close to the equator, no subtropical convergence zone occurs.

\section{Conclusions}

This study uses aqua-planet simulations with NASA/ Goddard's GEOS-5 GCM to analyse mechanisms for the formation and maintenance of the SACZ. The objectives of this study were twofold: (1) to investigate the effect of the latitude and strength of a synoptic-scale region of convection in the tropics (such as the Amazon Basin convection) on the formation of a subtropical convergence 
CONTROL Front Composites (120E)

(Rain, $850 \mathrm{mb}$ U,V, and SLP)

(a) Day -2

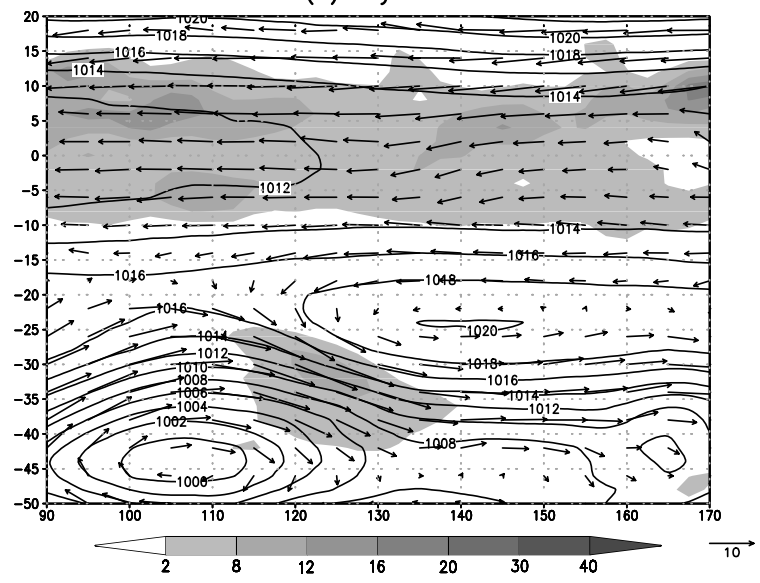

(b) Day -1

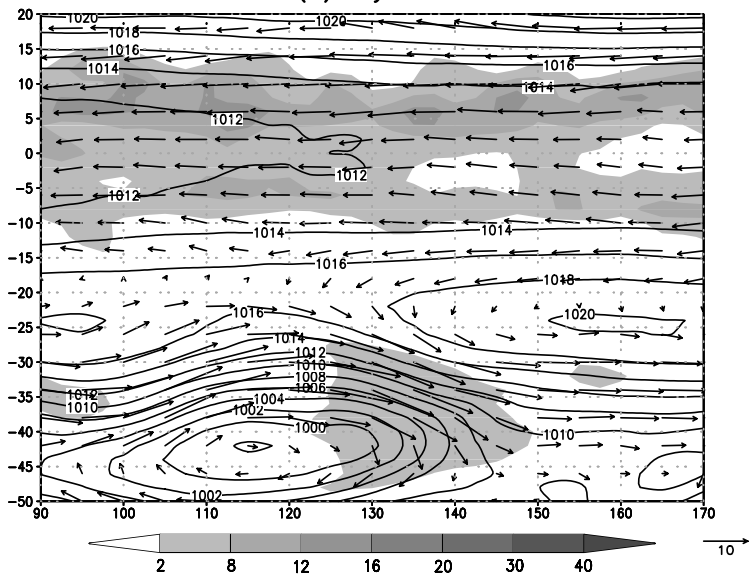

(c) Day 0

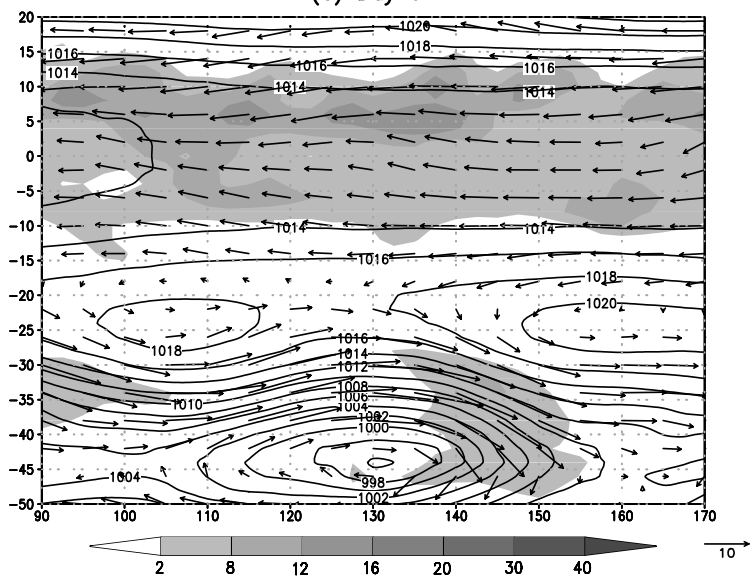

(d) Day +1

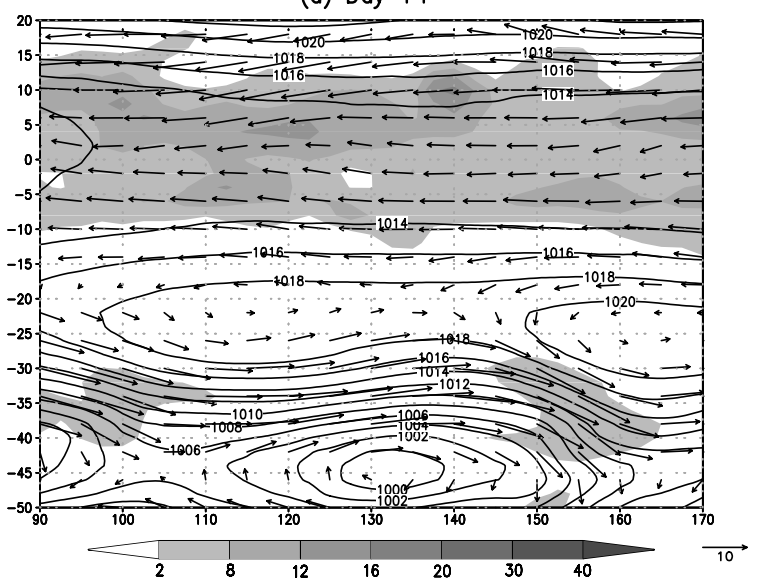

(e) Day +2

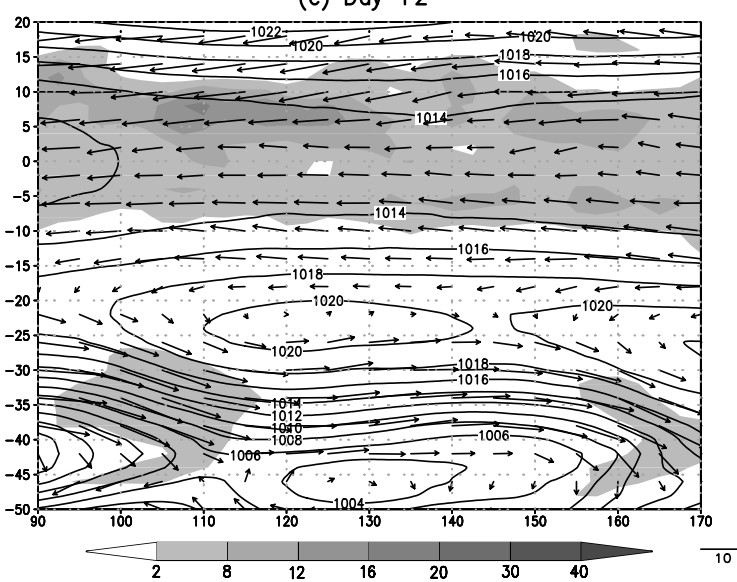

(f) Day +3

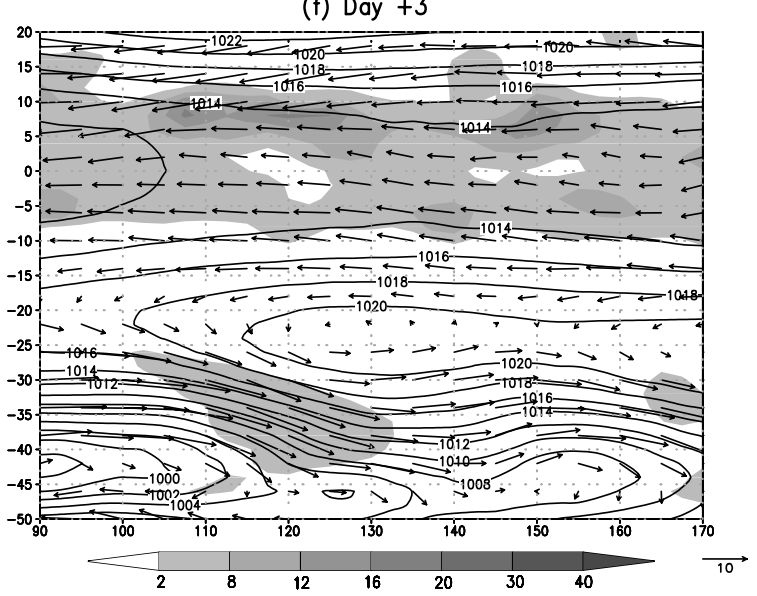

Figure 8. Same as Figure 5, but for frontal systems that passed far away from the model Amazon (at $\left.120^{\circ} \mathrm{E}\right)$ in experiment CONTROL.

zone (such as the SACZ) and (2) to investigate how changes in the structure and propagation of nearby midlatitude frontal systems help establish and maintain the subtropical convergence zone. Although our simulations are designed to mimic the effects of Amazon Basin rainfall on the formation and maintenance of the SACZ, the results of this study can easily be generalized to the formation and maintenance of other subtropical convergence zones around the world, e.g. the South Pacific and South
Indian Ocean convergence zones and the Mei-Yu front in Asia.

In the aqua-planet simulations, a circular patch of warm SSTs is used to represent the influence of the warm, moist summertime Amazon Basin on rainfall in the SAMS. The simulations presented here confirm previous results that show that the presence of a near-equatorial synoptic-scale region of enhanced convection such as the Amazon Basin summertime rainfall is necessary for 


\section{Vertically Integrated moisture flux \\ (Day 0 Front Composites)}

(a) CONTROL at $120 \mathrm{E}$

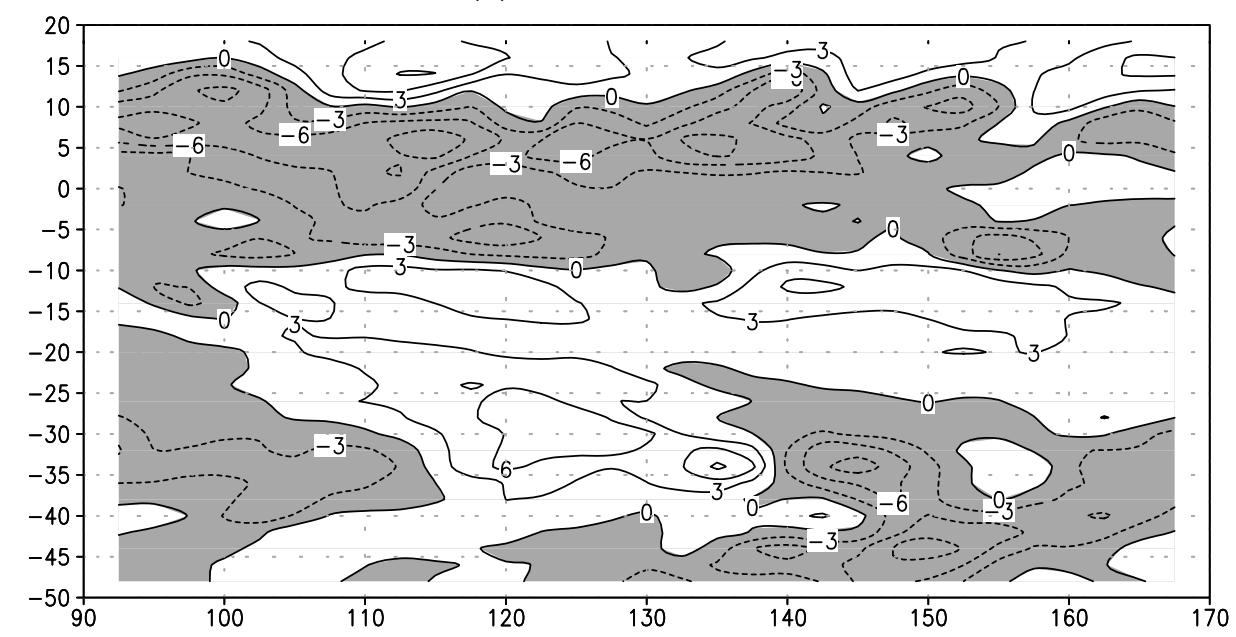

(b) WEAK

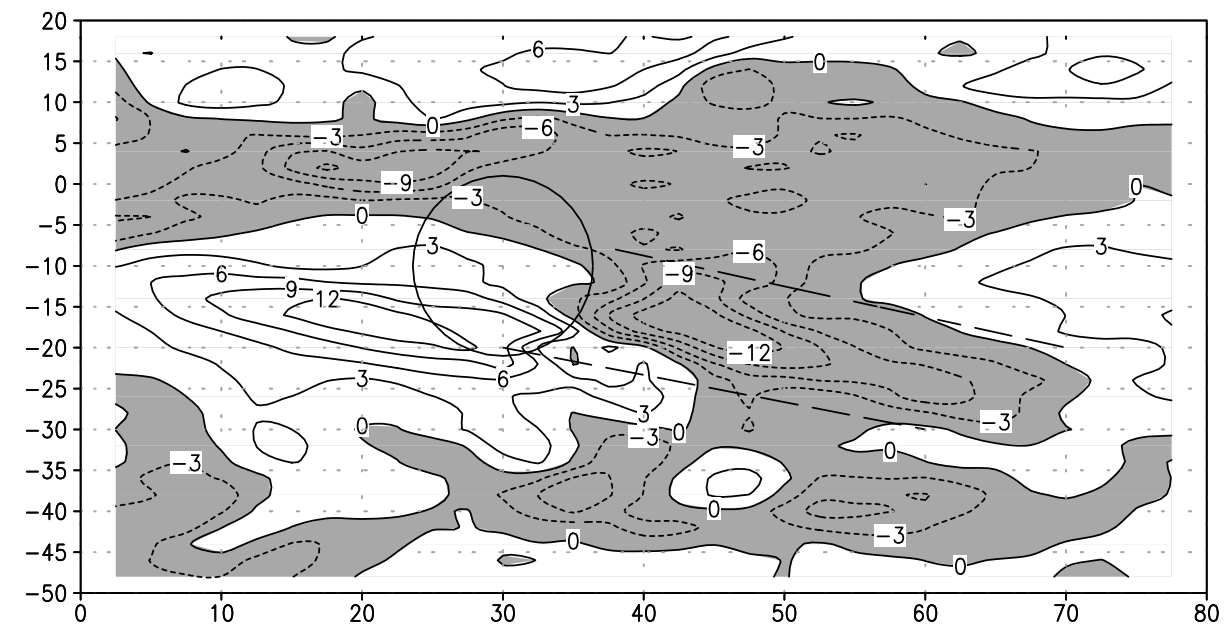

Figure 9. Day +1 composite rainfall (shaded, $\mathrm{mm} \mathrm{d}^{-1}$ ), vertically integrated moisture flux (contours, $\mathrm{mm} \mathrm{d}^{-1}$ ), and low-level winds (arrows, $\mathrm{m}$ $\mathrm{s}^{-1}$ ) for frontal systems in (a) CONTROL near $120^{\circ} \mathrm{E}$ and (b) WEAK near $50^{\circ} \mathrm{E}$.

the formation of a subtropical convergence zone such as the SACZ. The aqua-planet simulations indicate that the establishment of the aqua-planet SACZ is favoured primarily by the southward migration of the aqua-planet warm SST patch and secondarily by the intensity of the warm anomaly in the SST patch. This aqua-planet result is in agreement with observations (NR10) that the SACZ tends to form after the onset of the monsoon season in the Amazon Basin. The aqua-planet simulations presented in this study did not, however, address the issue of the observed abruptness of the onset of rainfall in the SACZ region.

An analysis of the synoptic-scale variability of rainfall in the aqua-planet shows the importance of mid-latitude frontal systems in the formation of the aqua-planet SACZ. A composite analysis of frontal systems that occurred in the aqua-planet simulations was used to study the changes in structure and propagation of cold fronts as they approach a synoptic-scale tropical region of enhanced convection. The composites show that as the synoptic-scale tropical region of enhanced convection (such as convection in the Amazon Basin) is strengthened and moved away from the equator, approaching mid-latitude frontal systems are able to penetrate into the subtropics and become stationary there for a few days, producing a subtropical convergence zone (such as the SACZ). The presence of a low-level northwesterly jet that extends from the tropics into higher latitudes is a distinctive characteristic of the composite frontal systems present in the simulations that have a robust SACZ feature (e.g. experiment CONTROL). This northwesterly low-level jet carries tropical moisture into the subtropics and fuels rainfall along the SACZ region. The composites show that fronts become stationary for a few days in the subtropics when they propagate past the longitude of the model Amazon Basin and that the moisture convergence associated with these frontal systems not only produces rainfall along the SACZ 


\section{WEAK Front Composites \\ (Rain, $850 \mathrm{mb} \mathrm{U}, \mathrm{V}$, and SLP)}

(a) Day -2

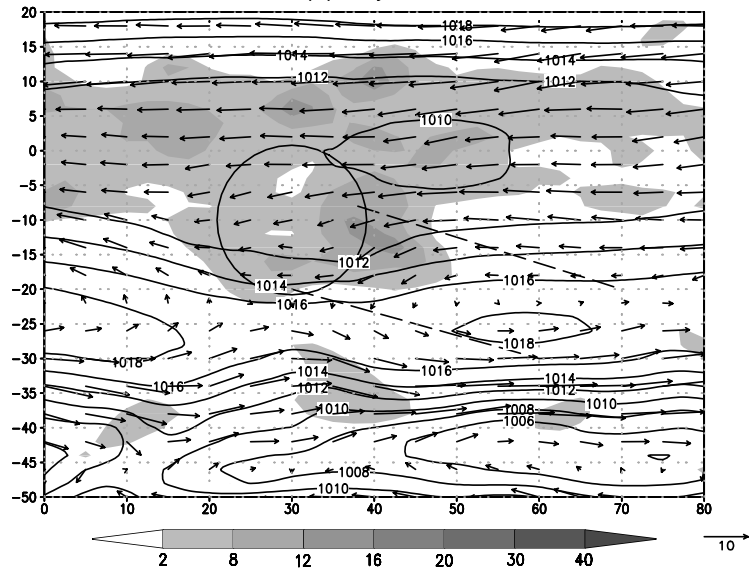

(b) Day -1

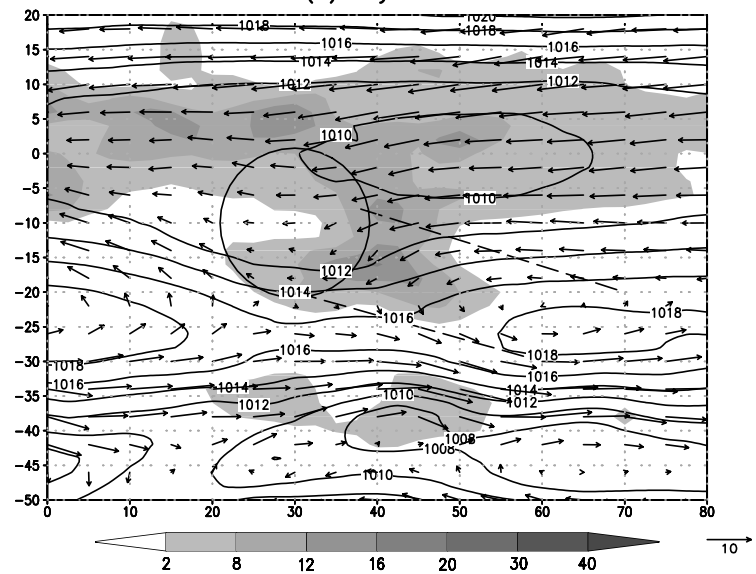

(c) Day 0

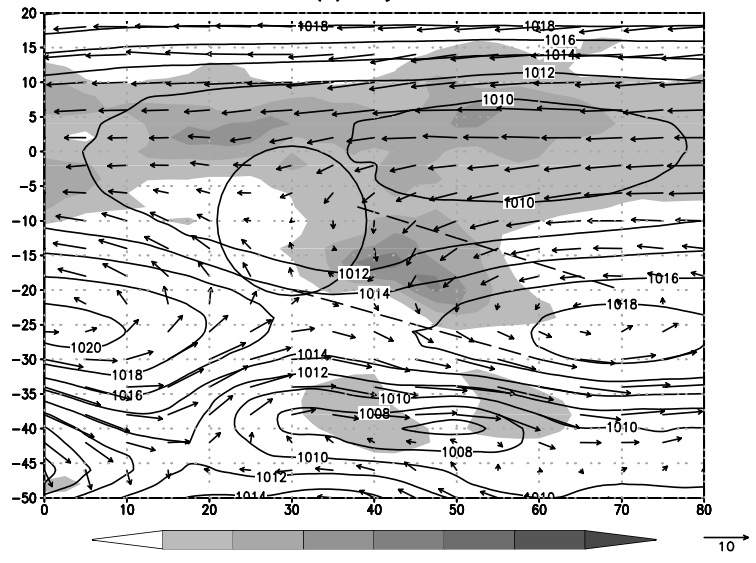

(d) Day +1

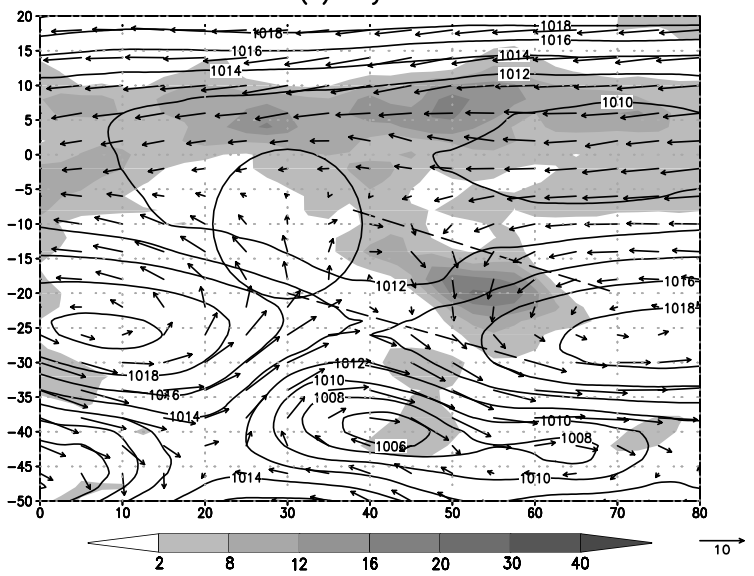

(e) Day +2

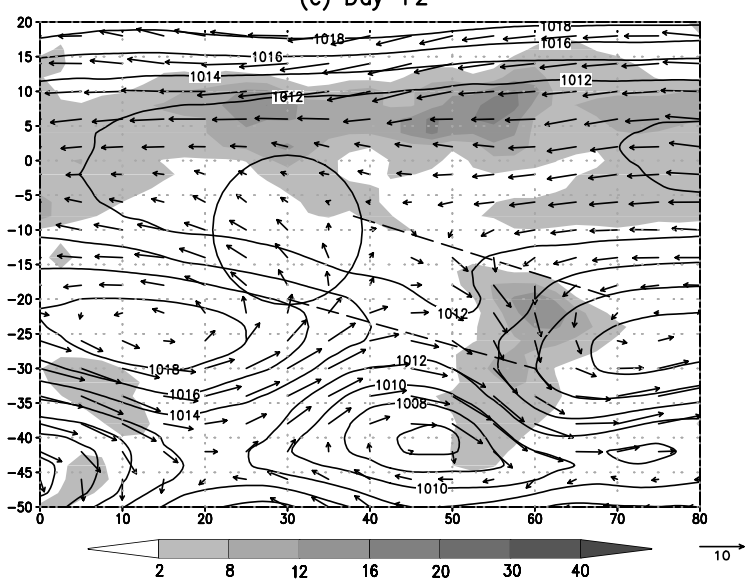

(f) Day +3

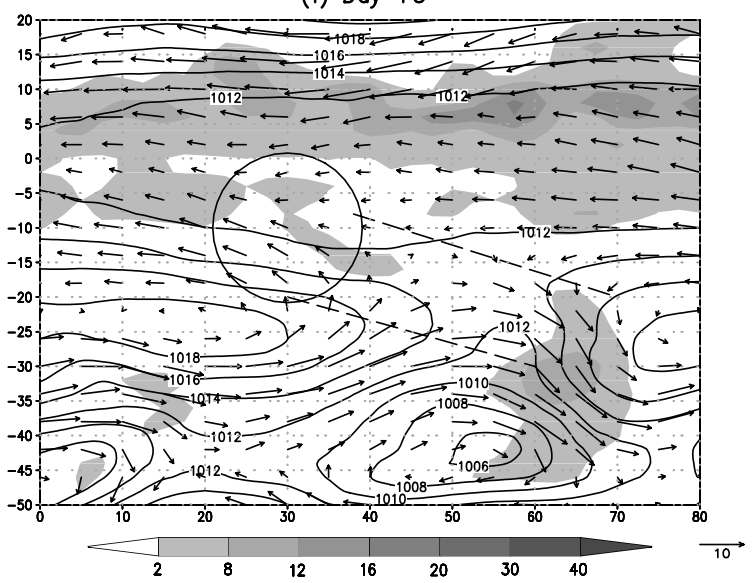

Figure 10. Same as Figure 5, but for experiment WEAK. The solid circle indicates the size and location of the imposed warm patch of SST and the dashed lines delimit the location of the model SACZ in experiment CONTROL.

region, but also organizes rainfall along a large portion of the northern model Amazon Basin. In fact, moisture flux convergence dominates as the source of moisture to feed rainfall in the model SACZ. Lastly the CONTROL simulation aqua-planet front composite presented here bears strong similarities with front composites that occur in the austral spring and summer over South America following the onset of the monsoon season in the SACZ (NRW11). The results shown here therefore support the observation in NRW11 that the formation of the SACZ is due to a change in the structure and propagation of midlatitude fronts, namely that fronts develop an equatorward 
extension and become stationary in the subtropics for a few days.

\section{Acknowledgements}

We wish to thank two anonymous reviewers for their thoughtful contributions to this manuscript. Dr Rosana Nieto Ferreira thanks the National Oceanic and Atmospheric Administration Climate and Global Change Program Climate Prediction Program for the Americas for its support of this research (Award Number: NA07OAR4310495). Dr Winston Chao was supported by NASA's Modeling, Analysis, and Prediction Program.

\section{References}

Bacmeister JT, Suarez MJ, Robertson FR. 2006. Rain re-evaporation, boundary-layer/convection interactions, and Pacific precipitation patterns in an AGCM. Journal of Atmospheric Sciences 63: 3383-3403.

Biasutti M, Battisti DS, Sarachik ES. 2004. Mechanisms controlling the annual cycle of precipitation in the tropical Atlantic sector in an atmospheric GCM. Journal of Climate 17: 4708-4723.

Carvalho LMV, Jones C, Liebmann B. 2002. Extreme precipitation events in southeastern South America and large-scale convective patterns in the South Atlantic Convergence Zone. Journal of Climate 15: $2377-2394$

Carvalho LMV, Jones C, Liebmann B. 2004. The South Atlantic Convergence Zone: intensity, form, persistence, and relationships with intraseasonal to interanual activity and extreme rainfall. Journal of Climate 17: 88-108.

Chao W, Chen B. 2001. The origin of monsoons. Journal of Atmospheric Sciences 58: 3497-3507.

Chao W, Chen B. 2004. Single and double ITCZs in an aqua-planet model with constant SST and solar angle. Climate Dynamics 22: 447-459, DOI: 10.1007/s00382-003-0387-4

Chou M-D, Suarez MJ. 1999. A solar radiation parameterization for atmospheric studies. NASA Technical Memo 104606, vol. 11, 40.

Chou M-D, Suarez MJ, Liang XZ, Yan MM-H. 2001. A thermal infrared radiation parameterization for atmospheric studies. NASA Technical Report Series on Global Modeling and Data Assimilation 104606, vol. 19, 56.

Figueroa SN, Satyamurty P, Silva Dias PL. 1995. Simulations of the summer circulation over the South American region with an eta coordinate model. Journal of Atmospheric Sciences 52: 1573-1584.

$\mathrm{Fu} \mathrm{R,} \mathrm{Li} \mathrm{W.} \mathrm{2004.} \mathrm{The} \mathrm{influence} \mathrm{of} \mathrm{the} \mathrm{land} \mathrm{surface} \mathrm{on} \mathrm{the} \mathrm{transition}$ from dry to wet season in Amazonia. Theoretical and Applied Climatology 78: $97-110$.

Gandu AW, Geisler JE. 1991. A primitive equations model study of the effect of topography on the summer circulation over tropical South America. Journal of Atmospheric Sciences 48: 1822-1836.

Garreaud RD. 2000. Cold air intrusions over subtropical South America: structure and dynamics. Mon. Wea. Rev. 128: 2544-2599.

Horel JD, Hahmann AN, Geisler JE. 1989. An investigation of the annual cycle of convective activity over the tropical Americas. Journal of Climate 2: 1388-1403.

Kodama Y-M. 1992. Large-scale common features of subtropical precipitation zones (the Baiu frontal Zone, the SPCZ, and the SACZ) Part I: characteristics of subtropical frontal zones. Journal of Meteorological Society of Japan 70: 813-835.

Kodama Y-M. 1993. Large-scale common features of subtropical precipitation zones (the Baiu frontal Zone, the SPCZ, and the SACZ)
Part II: conditions of the circulations for generating the STCZs. Journal of Meteorological Society of Japan 71: 581-610.

Kodama Y-M. 1999. Roles of the atmospheric heat sources in maintaining the subtropical convergence zones: an aqua-planet GCM study. Journal of Atmospheric Sciences 56: 4032-4049.

Kousky VE. 1988. Pentad outgoing longwave radiation climatology for the South American sector. Revista Brasileira de Meteorologia 3: $217-231$.

Lenters JD, Cook KH. 1995. Simulation and diagnosis of the regional South American precipitation climatology. Journal of Climate $\mathbf{8}$ 2988-3005

Li W, Fu R. 2004. Transition of the large-scale atmospheric and land surface conditions from the dry to the wet season over Amazonia as diagnosed by the ECMWF re-analysis. Journal of Climate 17: 2637-2651.

Li W, Fu R. 2006. Influence of cold air intrusions on the wet season onset over Amazonia. Journal of Climate 19: 257-275.

Liebmann B, Kiladis GN, Marengo JA, Ambrizzi T, Glick JD. 1999 Submonthly convective variability over South America and the South Atlantic Convergence zone. Journal of Climate 12: 1877-1891.

Liebmann B, Marengo JA. 2001. Interannual variability of the rainy season and rainfall in the Brazilian Amazon Basin. Journal of Climate 14: 4308-4318.

Lin S-J. 2004. A "vertically Lagrangian" finite-volume dynamical core for global models. Monthly Weather Review 132: 2293-2307.

Lock AP, Brown AR, Bush MR, Martin GM, Smith RNB. 2000. A new boundary layer mixing scheme. Part I: scheme description and single-column model tests. Monthly Weather Review 128: $1387-1399$.

Louis JF. 1979. A parametric model of vertical eddy fluxes in the atmosphere. Boundary Layer Meteorology 17: 187-202.

Marengo JA, Liebmann B, Kousky VE, Filizola NP, Wainer I. 2001. Onset and end of the rainy season in the Brazilian Amazon basin. Journal of Climate 14: 833-852.

Mathews AJ, Hoskins BJ, Slingo JM, Blackburn M. 1996. Development of convection along the SPCZ within a Madden-Julian Oscillation. Quarterly Journal of the Royal Meteorological Society 122 : 669-688.

Moorthi S, Suarez MJ. 1992. Relaxed Arakawa-Schubert: a parameterization of moist convection for general circulation models. Monthly Weather Review 120: 978-1002.

Nieto-Ferreira R, Rickenbach TM. 2010. Regionality of monsoon onset in South America: a three-stage conceptual model. International Journal of Climatology 31(9): 1309-1321, DOI: 10.1002/joc. 2161.

Nieto-Ferreira R, Rickenbach TM, Herdies DL, Carvalho LMV. 2003. Variability of South American convective cloud systems and tropospheric circulation during January-March 1998 and 1999. Monthly Weather Review 131: 961-973.

Nieto-Ferreira R, Rickenbach TM, Wright EA. 2011. The role of cold fronts in the onset of the monsoon season in the South Atlantic convergence zone. Quarterly Journal of the Royal Meteorological Society 137: 908-922, DOI: 10.1002/qj.810. 2011.

Raia A, Cavalcanti IF. 2008. The life cycle of the South American monsoon system. Journal of Climate 21: 6227.

Rickenbach TM, Nieto Ferreira R, Halverson J, Herdies DL, Silva Dias MAF. 2002. Modulation of convection in the southwestern Amazon basin by extratropical stationary fronts. Journal of Geophysical Research 107: 8040, DOI: 10.1029/2000JD000263.

Silva Dias PL, Schubert WH, DeMaria M. 1983. Large-scale response of the tropical atmosphere to transient convection. Journal of Atmospheric Sciences 40: 2689-2707.

Thorncroft CD, Hoskins BJ, McIntyre ME. 1993. Two paradigms of baroclinic wave life-cycle behavior. Quarterly Journal of the Royal Meteorological Society 119: 17-55.

Yoshikane T, Kimura F. 2003. Formation mechanism of the simulated SPCZ and Baiu Front using a regional climate model. Journal of Atmospheric Sciences 60: 2612-2632. 